\title{
THE RATE OF HETEROGENEOUS POLYMERIZATION IN WATER FOR THE ENCAPSULATION OF INORGANIC POWDER WITH POLYMERS
}

\author{
MASAHIRO HASEGAWA, Kunio ARAI AND SHOZABURo SAITO \\ Department of Chemical Engineering, Tohoku University, Sendai 980
}

Key Words: Chemical Reaction, Heterogeneous Polymerization, Encapsulation, Inorganic Powder, Polymerization Rate, Methyl Methacrylate, Calcium Carbonate

\begin{abstract}
The encapsulation of a fine inorganic powder for its surface modification was carried out by heterogeneous polymerization of methyl methacrylate in water. The powder used was calcium carbonate and the initiator was potassium persulfate. The surfactant, sodium dodecyl sulfate, was adsorbed onto the powder prior to the polymerization. The polymerizations were conducted with various amounts of adsorbate and at constant concentrations of the powder, monomer and initiator, under a nitrogen atmosphere in an agitated tank. Timeconversion curves obtained varied remarkably with the amount of adsorbed surfactant. A simulation of the rate of polymerization was attempted by application of kinetic models previously applied to soapless emulsion polymerization in the absence of powder.
\end{abstract}

\section{Introduction}

The technology of encapsulating a fine inorganic powder with organic polymers is useful for modifying the surface of the powder and improving its physical properties. ${ }^{5,8,10,11)}$ The authors have reported ${ }^{6,7)}$ a new process which makes possible the encapsulation of submicron-sized fine powders with a polymer film by heterogeneous polymerization in water in which the powders are well dispersed. An important factor in the new process is a pretreatment in which a surfactant is added at less than its critical micelle concentration $(\mathrm{CMC})$ into the reaction system prior to polymerization to bring about the formation of a polymerization locus on the surface of powders. In the present work, heterogeneous polymerization was carried out in the presence of fine powder and surfactant. The effect of the surfactant concentration on the polymerization rate is experimentally and theoretically investigated.

\section{Experimental}

Heterogeneous polymerization of methyl methacrylate (MMA) in water in the presence of calcium carbonate $\left(\mathrm{CaCO}_{3}\right)$ and sodium dodecyl sulfate (SDS) surfactant was carried out using potassium persulfate $\left(\mathrm{K}_{2} \mathrm{~S}_{2} \mathrm{O}_{8}\right)$ as initiator. The $\mathrm{CaCO}_{3}$ was $0.3-0.6 \mu \mathrm{m}$ in particle size range and $8.5 \mathrm{~m}^{2} / \mathrm{g}$ in BET specific surface area. The reagents were the same as described previously. ${ }^{6,7)}$

All the polymerizations were conducted in a nit-

\footnotetext{
Received June 3, 1987. Correspondence concerning this article should be addressed to S. Saito.
}

rogen atmosphere in an agitated tank reactor of about 10 liters. In Fig. 1 is shown a sketch of the reactor, which comprises a cylindrical glass vessel fitted with four baffle plates and a six-bladed turbine impeller. To avoid bubble production by the surfactant, a Teflon plate having the same diameter as the reactor was placed on the liquid surface.

The flow sheet of the experimental apparatus is shown in Fig. 2. The inorganic powder, distilled water and surfactant were charged into the reactor, and the mixture was stirred for $2 \mathrm{~h}$ at a slow rate of $150 \mathrm{rpm}$ to prevent bubble production. After monomer had been fed into the reactor, the polymerization was started by

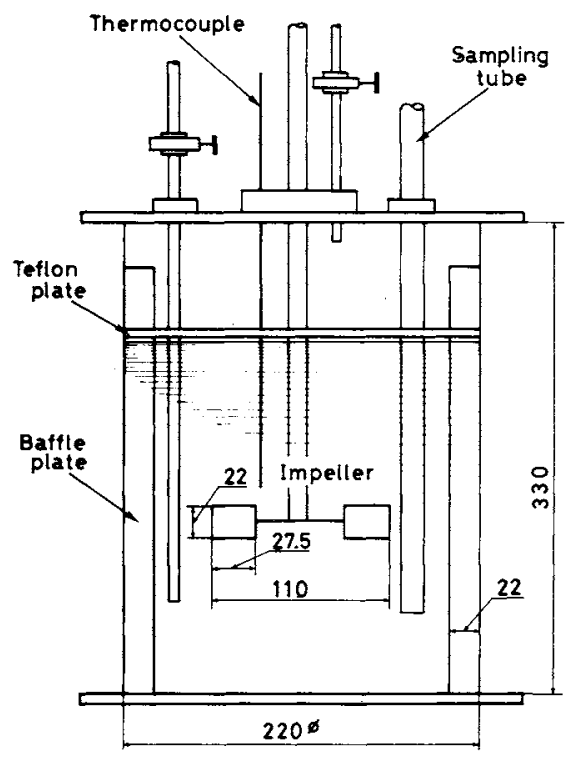

Fig. 1. Polymerization reactor 


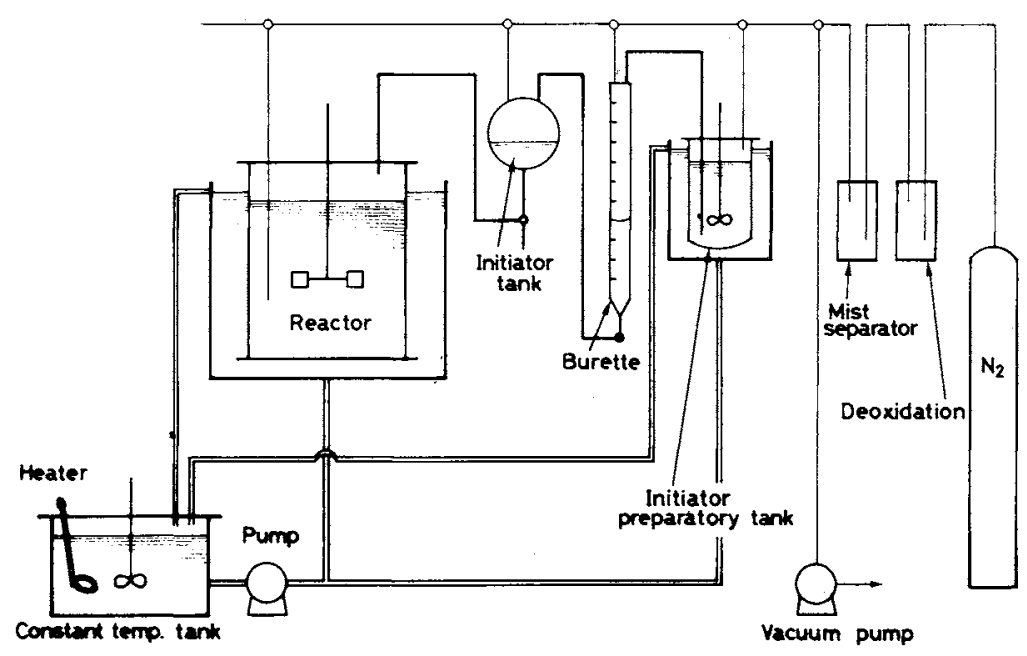

Fig. 2. Flow sheet of experimental apparatus

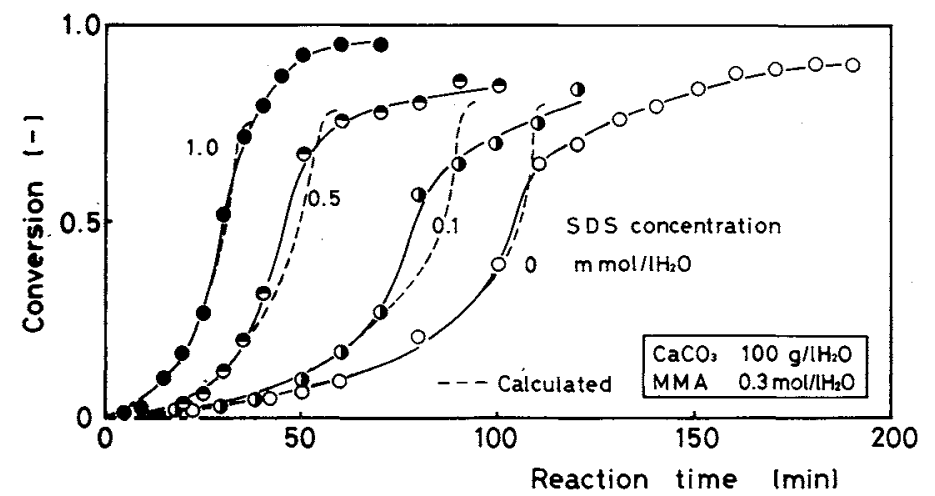

Fig. 3. Time-conversion curves for an SDS concentration range of 0 to $1 \mathrm{mmol} / l \mathrm{H}_{2} \mathrm{O}$

the addition of the initiator solution. During polymerization, the reaction mixture was stirred at a rate of $400 \mathrm{rpm}$ and the temperature was maintained at $60 \pm 1^{\circ} \mathrm{C}$. At appropriate intervals, the reaction mixture was sampled, filtered and dried under reduced pressure.

The polymerizations were first carried out at various concentrations of the powder and a constant $1 \mathrm{mmol} / l \mathrm{H}_{2} \mathrm{O}$ concentration of SDS. At a concentration of powder less than $60 \mathrm{~g} / l \mathrm{H}_{2} \mathrm{O}$, the polymer produced not only covered the powder surface but also formed many free polymer particles that were not involved in the covering. Furthermore, at a concentration of powder higher than $200 \mathrm{~g} / l \mathrm{H}_{2} \mathrm{O}$, the increased viscosity prevented adequate agitation of the reaction mixture and therefore subsequent polymerizations were carried out at a constant powder concentration of $100 \mathrm{~g} / l \mathrm{H}_{2} \mathrm{O}$.

The monomer-to-polymer conversion was determined by measuring polymer content in the reaction mixture by thermal balance. The molecular weight of polymer was measured by gel permeation chromatography. The amount of surfactant adsorbed by the powder was determined from the difference in surfactant concentration in the aqueous phase before and after adsorption. The surfactant concentration was measured by means of a Total Organic Carbon Analyzer (Beckman Co., Ltd., Model 915).

The measurement of monomer concentration on the polymerization loci was carried out according to Kanbe's procedure ${ }^{9)}$ as follows. The reaction mixtures sampled were divided into two parts. The first part was used to measure the polymer content and conversion of the sample in the manner described above. Excessive monomer droplets were removed from the second part and the monomer concentration in water phase was determined to be the saturated solubility of MMA $\left(0.15 \mathrm{~mol} / l \mathrm{H}_{2} \mathrm{O}\right.$ at $\left.60^{\circ} \mathrm{C}\right)$. The mixture was allowed to react until polymerization was complete and the polymer content was measured.

The monomer concentration in the polymerization locus was found by subtracting the polymer content of the first part and the amount of monomer in water phase from the polymer content of the second part.

\section{Results and Discussion}

\subsection{Polymerization and encapsulation}

Figures 3 and $\mathbf{4}$ show the time-conversion curves at various SDS concentrations. As shown in Fig. 3, with an SDS concentration range of $0-1 \mathrm{mmol} / l \mathrm{H}_{2} \mathrm{O}$, the 


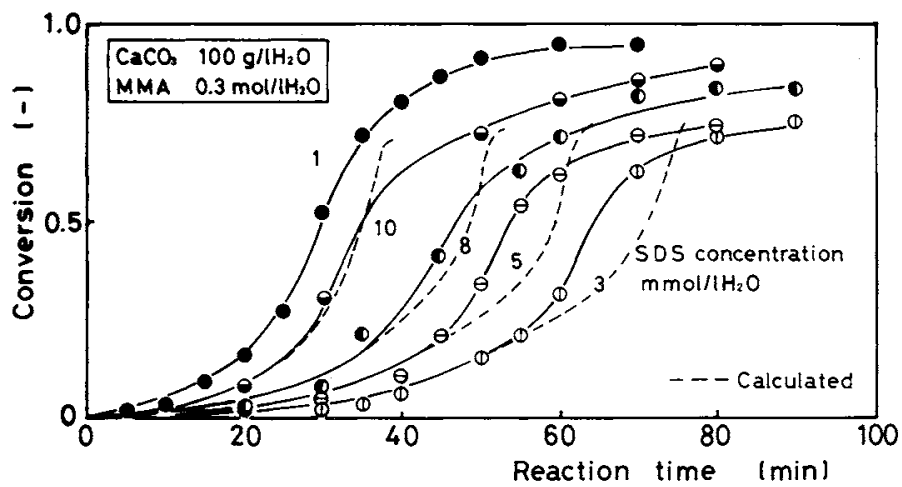

Fig. 4. Time-conversion curves for an SDS concentration range of 1 to $10 \mathrm{mmol} / l \mathrm{H}_{2} \mathrm{O}$

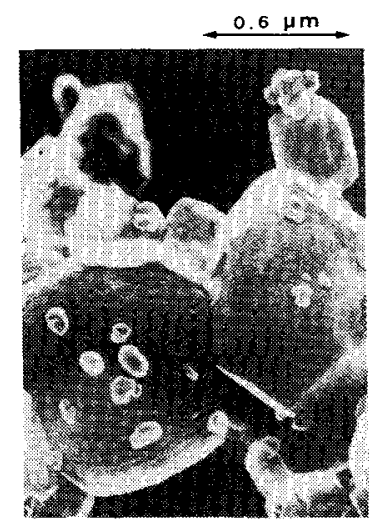

(a) Original $\mathrm{CaCO}_{3}$

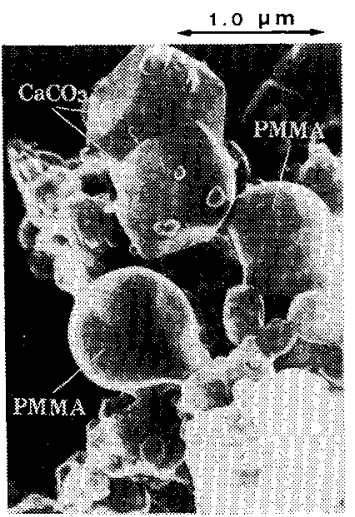

(b) $\mathrm{CaCO}_{3}-\mathrm{PMMA}$ obtained by polymerization without SD S

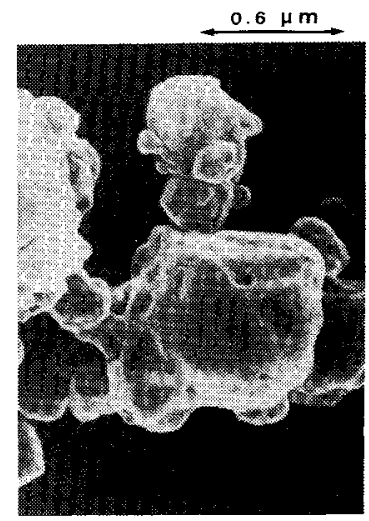

(c) $\mathrm{CaCO}_{3}-\mathrm{PMMA}$ obtained by polymerization

Fig. 5. Scanning electron micrographs of powders under various polymerization conditions: (a) original $\mathrm{CaCO}_{3}$; (b) and (c) $\mathrm{CaCO}_{3} 100 \mathrm{~g} / / \mathrm{H}_{2} \mathrm{O}$, MMA $0.3 \mathrm{~mol} / / \mathrm{H}_{2} \mathrm{O}$, SDS in (b) 0, in (c) $1 \mathrm{mmol} / / \mathrm{H}_{2} \mathrm{O}$; reaction temperature $60^{\circ} \mathrm{C}$; reaction time $60 \mathrm{~min}$

reaction time needed to attain a high conversion becomes shorter with an increase in the concentration of SDS added. Figure 4 shows the results when SDS concentration was increased from 1 to $10 \mathrm{mmol} /$ $l \mathrm{H}_{2} \mathrm{O}$. The lowest rate of polymerization occurred at an SDS concentration of $3 \mathrm{mmol} / l \mathrm{H}_{2} \mathrm{O}$.Thus, the time-conversion curves obtained varied remarkably with SDS concentration.

Figure 5 shows scanning electron micrographs of the powders: (a) original; (b) after polymerization, without SDS; and (c) after polymerization, with $1 \mathrm{mmol} / l \mathrm{H}_{2} \mathrm{O}$ of SDS. For the powder without SDS (micrograph (b)), the polymer particles formed grew to the same size as the powder particles themselves and are only partly attached to the powder surface. On the other hand, with SDS (micrograph (c)) the polymer formed a film on the powder surface. When SDS concentration was more than $1 \mathrm{mmol} / l \mathrm{H}_{2} \mathrm{O}$, the powder surface could be uniformly covered with the film polymer as shown in micrograph (c). However, at SDS concentrations of 3 and $5 \mathrm{mmol} / l \mathrm{H}_{2} \mathrm{O}$, the powder particles in the reaction mixture had a tendency to agglomerate, and the agglomerates were found from observation by electron microscopy to be encapsu-
Table 1. Adsorption of SDS on $\mathrm{CaCO}_{3}$

\begin{tabular}{cccc}
\hline $\begin{array}{c}\text { Total SDS } \\
\text { concentration } \\
{\left[\mathrm{mmol} / l \mathrm{H}_{2} \mathrm{O}\right]}\end{array}$ & $\begin{array}{c}\text { SDS concentration } \\
\text { in aqueous phase } \\
{\left[\mathrm{mmol} / l \mathrm{H}_{2} \mathrm{O}\right]}\end{array}$ & $\begin{array}{c}\text { Amount of } \\
\text { adsorbed SDS } \\
{\left[\mu \mathrm{mol} / \mathrm{g}-\mathrm{CaCO}_{3}\right]}\end{array}$ & $\begin{array}{c}\text { Surface } \\
\text { coverage } \\
\text { by SDS } \\
{[-]}\end{array}$ \\
\hline 0.1 & 0.080 & 0.20 & 0.008 \\
0.5 & 0.365 & 1.35 & 0.051 \\
1.0 & 0.656 & 3.44 & 0.129 \\
3.0 & 1.97 & 10.3 & 0.388 \\
5.0 & 2.74 & 22.1 & 0.831 \\
8.0 & 4.08 & 39.2 & 1.47 \\
10.0 & 5.93 & 40.7 & 1.53 \\
\hline
\end{tabular}

Adsorption conditions: $\mathrm{CaCO}_{3} 100 \mathrm{~g} / \mathrm{HH}_{2} \mathrm{O}, 60^{\circ} \mathrm{C}, 2 \mathrm{~h}$.

lated with polymer. Judging from the encapsulation state of the powder and the polymerization rate, a useful concentration in the present reaction system is considered to be around $1 \mathrm{mmol} / l \mathrm{H}_{2} \mathrm{O}$.

The fraction of the powder surface covered by the SDS is shown in Table 1. The surface coverage was calculated by assuming that the area occupied by a SDS molecule is $50 \mathrm{~A}^{2}$. Table 1 shows that monolayer adsorption is attained at around $6 \mathrm{mmol} / l \mathrm{H}_{2} \mathrm{O}$. At 
$1 \mathrm{mmol} / l \mathrm{H}_{2} \mathrm{O}$ SDS concentration, where the powder surface was favorably covered with polymer, the SDS surface coverage fraction is at most 0.13 , which is less than the value pertaining to a monolayer adsorption.

Figure 6 shows the molecular weight distribution of polymers produced at 0 and $1 \mathrm{mmol} / l \mathrm{H}_{2} \mathrm{O}$ SDS concentrations. Though all the distribution curves were unimodal, the molecular weight distributions of polymers formed without SDS (broken line) were broader than those formed at a $1 \mathrm{mmol} / l \mathrm{H}_{2} \mathrm{O}$ SDS concentration (solid line). The number-average molecular weights of the polymers without SDS were lower than those at $1 \mathrm{mmol} / l \mathrm{H}_{2} \mathrm{O}$. This suggested that the polymerization locus varied with the addition of SDS.

\subsection{Monomer concentration in the polymerization loci}

Information about monomer concentration in the polymerization locus is necessary to understand the rate of polymerization. With respect to monomer concentration in polymer particles of soapless emulsion polymerization, Arai et al. $^{3)}$ reported that the monomer concentration in polymer particles is approximately constant in the presence of monomer droplets and that it decreases in proportion to monomer-to-polymer conversion after the depletion of the droplets. The present polymerization system probably also exhibits this phenomenon.

In addition, our experiments have been aimed at establishing the initial monomer concentrations in the polymerization loci, $M_{p 0}$. Figure 7 shows the effect of SDS concentration on the monomer concentration in polymerization loci at a conversion less than 0.13 . It was found that all monomer concentrations measured were lower than those without SDS. This may occur due to the hydrophilic character of SDS molecules.

\subsection{Dispersibility of powder}

The addition of surfactant affects the dispersibility of the powder in the reaction system.

Figure 8 shows the relationships among surfactant concentration, sedimentation time and volume of sedimentation. Sedimentation time was taken as the time for the sedimental interface to reach half its original height. The volume of sedimentation was taken as the volume attained after the mixture had been allowed to stand for a week. Generally, the longer the sedimentation time and the smaller the volume of sedimentation, the more favorable is the dispersibility of the powder. As can be seen from the figure, the sedimentation time decreases with increasing SDS concentration, reaches a minimum around 3$5 \mathrm{mmol} / / \mathrm{H}_{2} \mathrm{O}$, and then increases. The volume of sedimentation has a maximum at an SDS concentration of about $3 \mathrm{mmol} / l \mathrm{H}_{2} \mathrm{O}$. Therefore, over an SDS concentration range of $3-5 \mathrm{mmol} / l \mathrm{H}_{2} \mathrm{O}$, $\mathrm{CaCO}_{3}$ powder tends to agglomerate. This agrees with SEM observations of products obtained by the

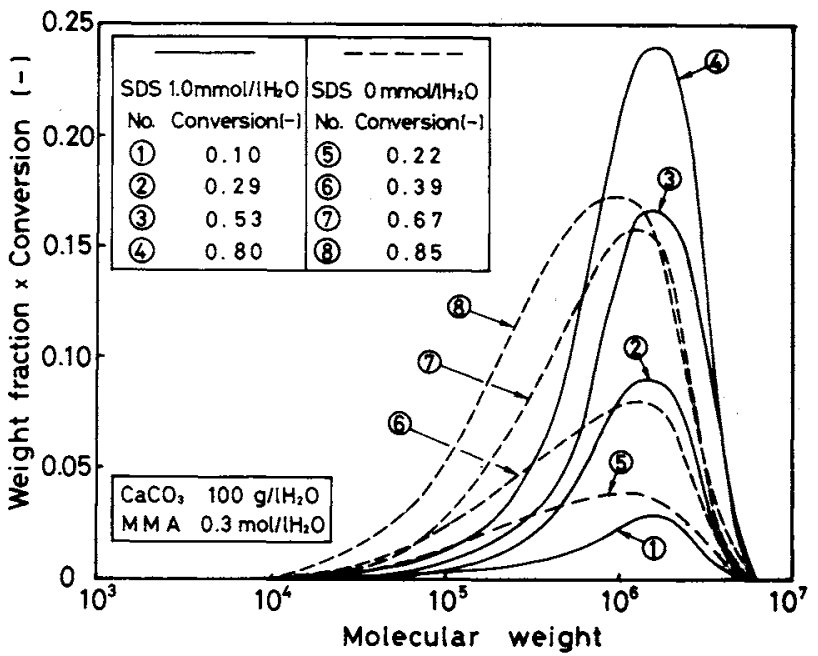

Fig. 6. Molecular weight distribution curves of polymer formed

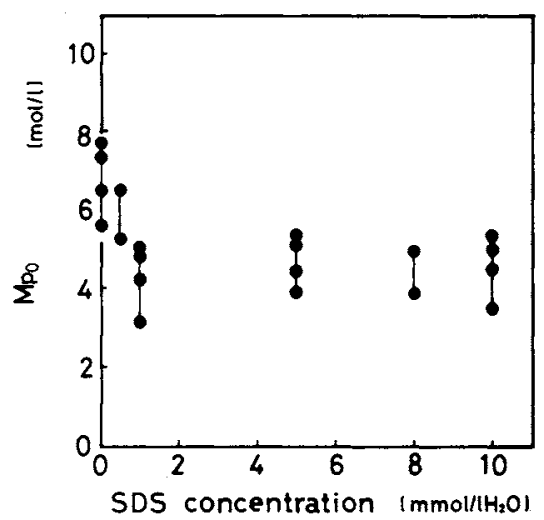

Fig. 7. Variation of $M_{p 0}$ with SDS concentration

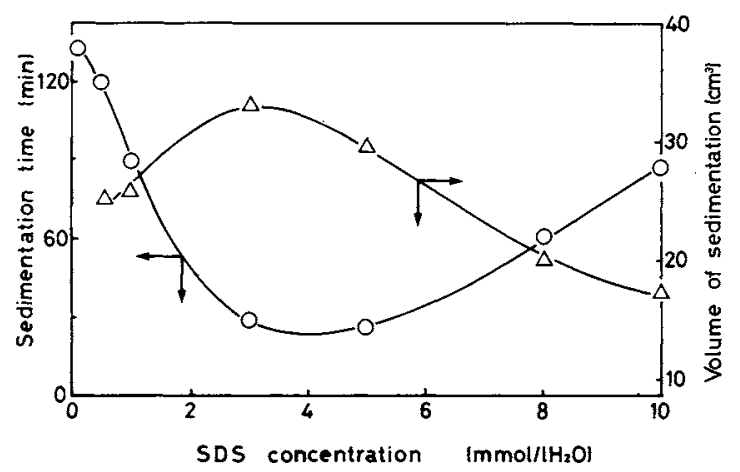

Fig. 8. Effect of SDS concentration on $\mathrm{CaCO}_{3}$ powder dispersibility

polymerization.

The variation in dispersibility of the powder is considered be connected with the rate of polymerization.

\section{Reaction Mechanism and Kinetic Model}

In the present system, polymerization may proceed mainly on part of the surface of the $\mathrm{CaCO}_{3}$ powder under favorable conditions for encapsulation. The 
formation of this layer is probably facilitated by the adsorption of SDS. Furthermore, a large number of polymerization loci can be considered to be formed on the surface of the powder. The adsorption layer on a single particle of powder is taken to be made up of separate patches. Therefore, the encapsulation mechanism can be explained as follows. The monomer is transferred from monomer droplets through the aqueous phase and swells in the SDS layers, into which polymer radicals in the aqueous phase also enter due to hydrophobic interaction. The greater part of polymerization proceeds only on the surface of the powder. Consequently, the surface of the powder will tend to be covered with filmlike polymer. The increase in amount of adsorbed SDS leads to an increase in number of polymerization loci, and tends to accelerate the rate of polymerization.

The decrease in rate of polymerization at 3 or $5 \mathrm{mmol} / l \mathrm{H}_{2} \mathrm{O}$ SDS concentration can be explained by a decrease in number of polymerization loci because of cohesion between the powder particles themselves.

We proposed a kinetic model which can adequately simulate the rate of free radical bulk polymerization of MMA and styrene. ${ }^{1)}$ This model is applicable to any heterogeneous polymerization. We have reported kinetic studies ${ }^{2-4)}$ of soapless emulsion polymerization in the absence of an inorganic powder based on the model we described in a previous work. ${ }^{1)}$ In this system, polymerization loci are only present in the polymer particles produced in the initial stage of polymerization.

In the present system, as mentioned above, it seems likely that polymerization loci are present in the SDS adsorption layers from the beginning of polymerization. Each of these is understood to act like a polymer particle in soapless emulsion polymerization in the absence of powder. Let $N_{p}$ be the total number of such loci on the powders. Then the overall rate of polymerization per unit volume of aqueous phase, $R_{p}$, is given by the following equation:

$$
R_{p}=\frac{d x}{d t} M_{0}=k_{p c} M_{E} \bar{n}^{*} N_{p} / N_{A}
$$

The $k_{p c}$ and $M_{E}$ values are calculated according to the bulk polymerization kinetic model. ${ }^{1}$

In the initial stage of polymerization the number of growing polymer radicals per polymerization locus, $\bar{n}^{*}$, is calculated by the procedure given by Arai et $a l^{2)}$ However, in a later stage of polymerization, the non-growing polymer radicals will increase with increasing volume fraction of polymer in the polymerization locus. In this case, the existence of nongrowing polymer radicals should not be neglected. Therefore, the numbers of growing and non-growing polymer radicals are estimated by taking the popu-
Table 2. Values of $N_{p}$ and $M_{p 0}$ used in the calculation

\begin{tabular}{ccc}
\hline $\begin{array}{c}\text { SDS } \\
\text { concentration } \\
{\left[\mathrm{mmol} / / \mathrm{H}_{2} \mathrm{O}\right]}\end{array}$ & $\begin{array}{c}N_{p} \\
{\left[1 / l \mathrm{H}_{2} \mathrm{O}\right]}\end{array}$ & $\begin{array}{c}M_{p 0} \\
{[\mathrm{~mol} / /]}\end{array}$ \\
\hline 0 & $9.7 \times 10^{14}$ & 7.0 \\
0.1 & $1.1 \times 10^{15}$ & 6.5 \\
0.5 & $3.5 \times 10^{15}$ & 5.0 \\
1.0 & $8.0 \times 10^{15}$ & 4.3 \\
3.0 & $1.2 \times 10^{14}$ & 5.3 \\
5.0 & $2.5 \times 10^{14}$ & 4.8 \\
8.0 & $8.0 \times 10^{14}$ & 4.3 \\
10.0 & $1.2 \times 10^{15}$ & 4.3 \\
\hline
\end{tabular}

lation balance of growing and total polymer radicals. Some parameters and constants used in the calculation have the same values as in the previous paper, ${ }^{1-3)}$ but monomer concentrations in polymerization loci used in the calculation are the observed values shown in Fig. 7.

At present it is not easy to determine the number of polymerization loci, $N_{p}$, and so we treat it as a fitting parameter which is determined from the initial rate of polymerization. When SDS is not added, $N_{p}$ can be estimated by the method for soapless emulsion polymerization in the absence of powder. ${ }^{2)}$ Table 2 shows the values of $N_{p}$ and $M_{p 0}$ used in the calculations.

Figures 3 and 4 show a comparison between timeconversion curves at various SDS concentrations and the results calculated (broken lines) from the present model. The calculated values agree with the experimental data except in the later stage of polymerization. The inability of the model to fit the data results from treating the rate of radical transfer to polymerization loci as a constant during polymerization.

The variation of the polymerization rate can be explained by considering the number of polymerization loci, $N_{p} . N_{p}$ is considered to increase essentially in proportion to the amount of adsorbed SDS. However, when powder particles themselves agglomerate due to the adsorption of SDS as seen in the present reaction system, the dispersibility of the powder must be sufficiently investigated to determine the $N_{p}$ values. Figure 9 shows the relationship between $N_{p}$ and apparent $\mathrm{CaCO}_{3}$ particle diameter calculated from sedimentation times in Fig. 4. The particle diameter directly indicates the dispersibility of the powder in the reaction system. The values of $N_{p}$ are found to be dependent on the dispersibility of the powder.

\section{Conclusion}

Fine inorganic powder can be usefully encapsulated with polymer in heterogeneous polymerization when surfactant is added at a concentration below its critical micelle concentration. The selection of con- 


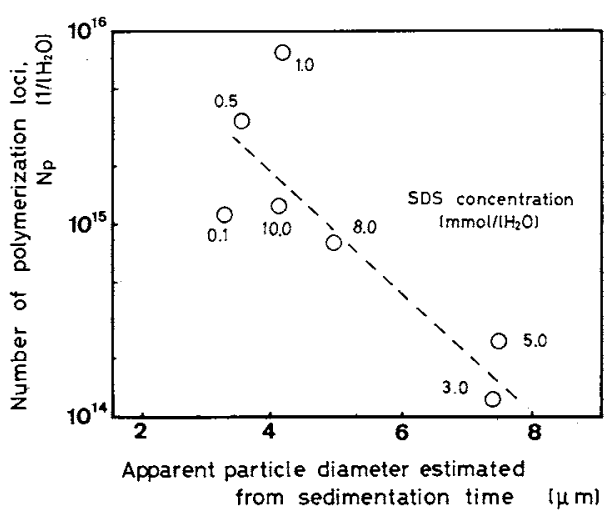

Fig. 9. Relationship between $N_{p}$ and apparent particle diameter of $\mathrm{CaCO}_{3}$ powder

centration of the surfactant is most important for satisfactory encapsulation of the powder. Surfactant concentration must be determined by investigating not only the amount of surfactant adsorbed on the powder but also the dispersibility of the powder in the reaction system. The rate of polymerization was found to vary with the quantity of surfactant adsorbed and could be correlated by kinetic models previously applied to soapless emulsion polymerization in the absence of powder.

\section{Nomenclature}

$k_{p c}=$ chemical reaction controlled-rate constant for propagation process

$[l /(\mathrm{mol} \cdot \mathrm{s})]$

\begin{tabular}{|c|c|c|c|}
\hline$M_{E}$ & & $\begin{array}{l}\text { monomer concentration around a } \\
\text { chain end }\end{array}$ & $\begin{array}{l}\text { polymer } \\
\qquad[\mathrm{mol} / l]\end{array}$ \\
\hline$M_{p 0}$ & & $\begin{array}{l}\text { initial monomer concentration in } \\
\text { polymerization locus }\end{array}$ & {$\left[\mathrm{mol} / / \mathrm{H}_{2} \mathrm{O}\right]$} \\
\hline$M_{0}$ & $=$ & initial monomer concentration & {$\left[\mathrm{mol} / / \mathrm{H}_{2} \mathrm{O}\right]$} \\
\hline$N_{A}$ & $=$ & Avogadro's number & {$[1 / \mathrm{mol}]$} \\
\hline$N_{p}$ & $=$ & number of polymerization loci & {$\left[1 / / \mathrm{H}_{2} \mathrm{O}\right]$} \\
\hline $\bar{n}^{*}$ & & $\begin{array}{l}\text { average number of radicals per } \\
\text { polymerization locus }\end{array}$ & \\
\hline$R_{p}$ & $=$ & overall rate of polymerization & {$\left[\mathrm{mol} /\left(l \mathrm{H}_{2} \mathrm{O} \cdot \mathrm{s}\right)\right]$} \\
\hline$t$ & $=$ & reaction time & \\
\hline$x$ & $=$ & conversion of monomer to ploym & \\
\hline
\end{tabular}

\section{Literature Cited}

1) Arai, K. and S. Saito: J. Chem. Eng. Japan, 9, 302 (1976).

2) Arai, M., K. Arai and S. Saito: J. Polym. Sci., Polym. Chem. $E d ., 17,3655$ (1979).

3) Arai, M., K. Arai and S. Saito: J. Polym. Sci., Polym. Chem $E d ., 18,2811(1980)$

4) Arai, K., M. Arai, S. Iwasaki and S. Saito: J. Polym. Sci., Polym. Chem. Ed., 19, 1203 (1981).

5) Fukano, K. and E. Kageyama: J. Polym. Sci., Polym. Chem. $E d ., 13,1309$ (1975).

6) Hasegawa, M., K. Arai and S. Saito: J. Polym. Sci., Polym. Chem. Ed., 25, 3117 (1987).

7) Hasegawa, M., K. Arai and S. Saito: to be published in $J$. Polym. Sci., Polym. Chem. Ed.

8) Hosoi, F. and K. Makuuchi: Kogyo Zairyo, 33, 60 (1985).

9) Kanbe, K.: M. Eng. Dissertation, Tohoku University (1974).

10) Yamaguchi, T., H. Tanaka, T. Ono, M. Endo, H. Ito and O. Itabashi: Kobunshi Ronbunshu, 32, 120 (1975).

11) Yamaguchi, T., T. Ono, M. Nozawa, M. Sekine, T. Iwai and T. Okada: Kobunshi Ronbunshu, 40, 259 (1983). 